\title{
PELATIHAN ON-LINE PEMBUATAN PERANGKAT HAND SANITIZER BERBAHAN NON-ALKOHOL PADA PEMUDA BINAAN
}

\section{ON-LINE TRAINING FOR MAKING HAND SANITIZER NON-ALCOHOL MATERIALS IN ASSISTED YOUTH}

\author{
Mochamad Lazuardi ${ }^{1}$, Hani Pumeriastuti ${ }^{2}$, Eka Pramyrtha Hestianah ${ }^{3}$ \\ ${ }^{1}$ Departemen Kedokteran Dasar Veteriner, ${ }^{2}$ Departemen Patologi, ${ }^{3}$ Departemen \\ Histologi Fakultas Kedokteran Hewan Universitas Airlangga, Jl. Mulyorejo Kampus C \\ Unair, Surabaya 60115 \\ email: lazuardi @fkh.unair.ac.id
}

\begin{abstract}
Training on non-alcohol based hand sanitizer (HS) was conducted for assisted youth in five districts, namely Gresik, Bojonegoro, Lamongan, Probolinggo and Nganjuk for three days. In the training, competency strengthening was carried out, namely theory and practicum, ending with evaluation of activities. During the implementation of theory and practicum, training materials were provided using social media facilities in the form of WhatsApp and e-mail. Specifically for coordination with participants, a training group was created using social media. The results of the training evaluation turned out that in terms of strengthening the competence of knowledge in making HS and working mechanisms of HS, it was increasing. In terms of straightening the meaning of HS production to be more focused according to the basis of science or good manufacturing practices (GMP). Thus, youth assisted with criteria include youth who are able to pass on knowledge to all young people in their respective districts. Furthermore, the knowledge and skills of the assisted youth in making HS based on non-alcoholic substances will be more agile and targeted. Thus, in reality, the training on making non-alcohol based HS has made the assisted youths become pioneers at the end of the line to pass on their knowledge. The conclusion in the implementation of this training is that the assisted youth are capable and ready to make non-alcohol-based HS as well as being ready to produce for a small scale while showing real work to be transmitted (98\%).
\end{abstract}

Key words: Anti-covid-19, non-alcohol, antiseptic, disinfectiion, boric acid

\begin{abstract}
abstrak
Telah dilakukan pelatihan pembuatan hand sanitizer (HS) berbasis non-alkohol terhadap pemuda binaan di lima kabupaten yaitu Gresik, Bojonegoro, Lamongan, Probolinggo dan Nganjuk selama tiga hari. Dalam Pelatihan tersebut dilakukan pemberian penguatan kompetensi yaitu teori dan praktikum diakhiri dengan evaluasi kegiatan. Selama berlangsung pelaksanaan teori dan praktikum, materi pelatihan diberikan menggunakan fasilitas media sosial berupa whatsapp dan e-mail. Khusus koordinasi dengan peserta dilakukan pembuatan grup pelatihan menggunakan media sosial. Hasil evaluasi pelatihan ternyata dari segi penguatan kompetensi pengetahuan pembuatan HS dan mekanisme kerja HS, makin meningkat. Segi pelurusan pengertian produksi HS menjadi makin terarah sesuai basis ilmu pengetahuan atau cara pembuatan obat yang baik (CPOB). Dengan demikian pemuda binaan dengan kritetria termasuk pemuda yang
\end{abstract}


sanggup menularkan ilmu ke seluruh masyarakat muda di kabupaten masing-masing. Lebihlanjut pengetahuan dan ketrampilan pemuda binaan dalam membuat HS berbasis bahan non-alkohol makin cekatan dan terarah. Dengan demikian seacara nyata pelatihan pembuatan HS berbasis non-alkohol telah menjadikan pemuda binaan sebagai pelopor di ujung garis untuk menularkan ilmunya. Kesimpulan dalam pelaksanaan pelatihan ini adalah para pemuda binaan telah sanggup dan siap membuat HS berbasis non-alkohol sekaligus siap berproduksi untuk skala kecil sambil memperlihatkan karya nyata untuk ditularkan $(98 \%)$.

Kata kunci: Anti covid-19, non-alkohol, antiseptik, disinfektan, boric acid

\section{PENDAHULUAN}

Diketahui bahwa wilayah penyangga Kota Surabaya seperti Kabupaten Gresik, Lamongan, Bojonegoro, Probolinggo dan Nganjuk adalah kabupaten yang memiliki potensi besar sebagai wilayah satelit untuk pengembangan sumber daya manusia. Sementara diketahui pula bahwa lima kabupaten tersebut memiliki permasalah dengan penyebaran kasus covid-19 dan diwilayah tersebut masyarakat setempat mengalami kesulitan untuk mendapatkan bahan-bahan antisepetik dan disinfektan yang bersifat anti covid-19 (Lazuardi et al., 2020). Persoalan tersebut menjadi semakin menonjol manakala akses untuk mendapatkan bahan-bahan kimia anti covid-19 di lima kabupatan tersebut tidak pernah mudah. Hal tersebut dapat dimengerti sebab bahan-bahan kimia tersebut sudah habis dilingkungan kota Surabaya.

Analogi paparan tersebut di atas, maka konsep solusi yang ditawarkan adalah meningkatkan pengetahuan Sumer Daya Manusia (SDM) mengenai bahan-bahan antiseptik desinfektansi yang mampu digunakan sebagai anti covid-19. Konsep solusi tersebut dapat diterapkan melalui pembinaan sekaligus penguatan kompetensi terhadap sasaran antara SDM di lima kabupaten tesebut. Model tersebut pernah dicobakan dikabupaten sidoarjo tahun 1990. Tujuan penguatan kompetensi melalui program pelatihan adalah menjadikan SDM di wilayah kabupaten tersebut menjadi lebih inovatif dan kreatif dalam menyikapi kelangkaan senyawa kimia anti covid-19 (Lazuardi et al., 2019). Secara teoritis konsep peningkatan SDM disuatu wilayah, amat sangat menguntungkan mengingat akan memiliki dampak esensial lain yaitu meningkatkan mutu kehidupan di wilayah tersebut. Pola induksii tersebut akan mempercepat peningkatan kompetensi secara menyeluruh dan cepat. Teknik tersebut juga dikembangkan oleh beberapa pelatih menggunakan konsep live skill (Bambang dan Lazuardi, 2000). Pelatihan kompetensi akan lebih berdayaguna bila dikembangkan secara bertingkat dimulai dari pemberian asupan teori dan dilanjutkan dengan praktikum, dengan demikian akan mudah menilai kelemahan-kelemahan yang ada (United Nations Conference On Trade and Development, 2020). Teknik lain yang dapat dimanfaatkan adalah pelatihan berbasis internet (E-Training) dan dapat digunakan untuk negara-negara berkembang (Fawzieh, 2017). Pelatihan berbasis internet yang dimaksud menggunakan fasilitas layanan jasa situs e-training dan ditawarkan khusus untuk kegiatan pelatihan. Teknik pelatihan ini pada akhirnya berkembang setelah muncul masalah pandemi covid-19 yang menyebar ke seluruh dunia (Ahmed et al., 2020). Model training tersebut pada akhirnya banyak dimodifikasi dan mennjadi contoh khusus dalam pilihan model training. 
Tinjauan teoritik mengenai e-training tentang pembuatan hand sanitizer di masa pandemik covid-19, banyak dilakukan di negara-negara empat musim. Di Indonesia teknik e-training mengenai hand sanitizer baru diketahui pada bulan agustus 2020. Pada training tersebut telah dikembangkan metode pelatihan berbasis modifikasi live skill dengan pola seperti mengacu pada Lazuardi (2011). Modifikasi yang dimaksud adalah menggunakan pola co-worker namun mandiri dan di evaluasi secara on-line. Pola tersebut pada akhirnya akan menimbulkan semangat untuk mencapai keberhasilan yaitu berhasil mengaplikasikan target pelatihan sesuai tuntunan tertulis maupun tidak tertulis (Jane et al., 2020). Model tersebut sangat sesuai bila digunakan untuk negara-negara berkembang, dengan pola pemikiran diperlukan suatu bentuk percontohan selanjutnya peserta training diminta untuk mengikuti pembimbing dan diwajibkan untuk membuat ulangan secara mandiri. Pola tersebut juga sesuai untuk bidang-bidang kedokteran yang masih tergolong baru memulai dalam kegiatan e-training. Bidang-bidang kedokteran hewan pada hakekatnya tidak berbeda jauh dengan bidang kedokteran dalam menyikapi kegiatan e-training, sebab bidang kedokteran hewan membutuhkan pula pelatihan berbasis hands-on sehingga lebih melatih ketrampilan dalam pelaksanaannya. Khusus mengenai pengetahuan formulasi pembuatan hands sanitizer, pada dasarnya membutuhkan pelatihan yang disebut ketrampilan. Dengan demikian peserta pelatihan dapat mengerti tatacara formulasi berbasis sains yang diterapkan. Pola pelatihan tersebut semasa pandemi covid-19, sangat dianjurkan oleh Badan Kesehatan Dunia terutama untuk negara-negara berkembang namun bahan-bahan untuk pembuatan hands sanitizer berlimpah sementara sumber daya manusia kurang dapat membudidayakan (World Health Organization, 2006). Model tersebut sangat sesuai diterapkan di Indonesia termasuk di Jawa Timur dengan tingkat kompetensi sumberdaya manusia yang perlu di dorong lebih lanjut.

Terkait paparan tersebut di atas, maka dilakukan pelatihan berbasis on-line untuk meningkatkan kompetensi pada kabupaten-kabupaten di wilayah jawa timur mengenai peningkatan pengetahuan dan ketrampilan pembuatan hand sanitizer. Adapun kabupaten yang terpilih adalah Gresik, Lamongan Bojonegoro Probolinggo dan Nganjuk, dengan dasar pemilihan adalah lima kabupaten tersebut merupakan kabupaten potensial untk dikembangkan terutama sumber daya manusia. Alasan tersebut didasarkan bahwa lima kabupaten tersebut merupakan kabupaten binaan Universitas Airlangga. Sebagai sasaran target peningkatan sumber daya manusia yang akan dibina adalah anak-anak muda berlatar belakang kesehatan yang mampu menginduksi pengetahuan pelatihan untuk disebarkan lebihlanjut ke kalangan insan masyarakat di lima kabupaten tersebut. Manfaat pelatihan berbasis e-training tentang formulasi dan produksi hands sanitizer adalah masyarakat akan mendapat sentuhan pengetahuan dari kelompok pemuda inti binaan tentang pembuatan hand sanitizer. Harapan lebih lanjut adalah lima kabupaten tersebut mampu mengatasi kelangkaan hand sanitizer menggunakan teknik produksi mandiri. Seandainya dalam fakta sehari-hari bahan dasar non-alkohol yang paling dianjurkan, hal tersebut disebabkan 5 hal keuntungan yaitu (1) tidak terbakar, (2) tidak mengiritas anak-anak dan orang tua, serta (3) baya terjangkau, (4) bahan-bahan dasar mudah ditemukan di kelima kabupaten tersebut. 


\section{METODE PENGABDIAN MASYARAKAT}

Rancangan kegiatan dilakukan secara e-training seperti uraian Fawzieh (2017), dengan tahapan dua aktivitas yaitu: (1) Penguatan kompetensi teoritik dan (2) dilakukan tuntunan pengembangan ketrampilan. Dua bagian tersebut pada akhirnya akan dilakukan evaluasi baik pengetahuan maupun ketrampilan. Dalam pelaksanaanya menggunakan pendekatan pre-post training method dan evaluasi dilakukan menggunakan uji t sebelum perlakuan dan pasca perlakuan dengan uji statistik 17.0 SPSS siknifikansi 5\%. Sasaran pengabdian pada masyarakat adalah pemuda binaan di lima kabupaten yaitu Gresik, Lamongan Bojonegoro, Probolinggo dan Nganjuk. Setiap kabupaten ditetapkan 5 (lima) peserta pemuda binaan dengan pertimbangan seperti ketentuan di bawah (Persamaan 1). Dalam persamaan 1, diketahui nilai adalah 1,96 dan $Z_{\beta}$ pada tingkat kesalahan $5 \%$ bernilai 1,645 (uji dua sisi). Asumsi toleransi harga beda (d) rerata peningkatan pembangunan antar kecamatan setiap kabupaten dari 5 kabupaten sekitar 3,62\%. Sedangkan nilai Simpang baku (Sa) peningkatan pembangunan antar kecamatan dalam 5 kabupaten $=1,7$ sedangkan simpang baku ( $\mathrm{Sb})$ kelompok antar kecamatan diluar 5 kabupaten $=1,4($ Ida, 2017). Dengan demikian nilai $\mathrm{N}$ yang merupakan ketentuan jumlah pemuda binaan yang di latih adalah 4,88 dan dibulatkan menjadi 5 pemuda binaan.

Persamaan 1.

$$
N=\frac{\left[\left(Z_{1}-\frac{\alpha}{2}\right)+Z_{\beta}\right]}{\frac{(d)^{2}}{(S a)^{2}+(S b)^{2}}}
$$

Dalam pelaksanaan praktikum akan dilakukan pembuatan HS dengan bahan-bahan (1) asidum boricum 3\%, (2) oleum citricum 2\% dan (3) aquademineralisata sampai dengan $100 \mathrm{~mL}$. Bahan-bahan praktikum bersifat pro analisis, dengan demikian pengotor bahan praktikum tidak ditemui. Cara pembuatan HS berbasis non alkohol adalah sebagai berikut:

Asidum boricum 3 gram dilakukan upaya penambahan aquademineralisata sampai dengan $70 \mathrm{~mL}$ dan ditambahkan $2 \mathrm{ml}$ Oleum citricum dan dilakukan pengicokan serta ditambahkan perlahan-lahan aquademineralisata sampai dengan $100 \mathrm{~mL}$. Selanjutnya semua sediaan yang telah dicampurkan dimasukkan dalam botol bening dan ditutup. Selanjutnya dilakukan pengukuran $\mathrm{pH}$ menggunakan $\mathrm{pH}$ meter tipe Metrolom

\section{HASIL DAN PEMBAHASAN}

Hasil penerimaan calon pemuda binaan di lima kabupaten menunjukkan hasil sebagai berikut (Tabel 1) 
Tabel. 1. Peserta pelatihan pemuda binaan lima kabupaten pembuatan hand sanitizer berbasis non-alkohol

\begin{tabular}{|c|c|c|c|c|}
\hline Kabupaten & Kecamatan & $\begin{array}{l}\text { Jumlah pemuda } \\
\text { binaan }\end{array}$ & $\begin{array}{l}\text { Latar belakang } \\
\text { pendidikan }\end{array}$ & Jenis kelamin \\
\hline \multirow{6}{*}{ Bojonegoro } & Kauman & 3 & $\begin{array}{l}\text { Sarjana } \\
\text { keperawatan }\end{array}$ & \multirow[t]{2}{*}{ Wanita } \\
\hline & & & Sarjana & \\
\hline & & & Sarjana & Pria \\
\hline & Dander & 1 & $\begin{array}{l}\text { Sekolah Menengah } \\
\text { Atas }\end{array}$ & Wanita \\
\hline & Sugih waras & 1 & Mahasiswa & Pria \\
\hline & Temayang & 1 & Mahasiswa & Pria \\
\hline \multirow{5}{*}{ Gresik } & Benjeng & 1 & $\begin{array}{l}\text { Sekolah Menengah } \\
\text { Atas }\end{array}$ & Pria \\
\hline & Menganti & 1 & Sarjana & Pria \\
\hline & Kebomas & 2 & Sarjana Akutansi & Pria \\
\hline & & & Mahasiswa & \\
\hline & Driyorejo & 1 & Mahasiswa & Pria \\
\hline \multirow{5}{*}{ Lamongan } & Maduran & 1 & Sarjana & Pria \\
\hline & Babat & 3 & $\begin{array}{l}\text { Sekolah Menengah } \\
\text { Atas }\end{array}$ & Wanita \\
\hline & & & Sarjana & \\
\hline & & & $\begin{array}{l}\text { Sekolah Menengah } \\
\text { Atas }\end{array}$ & Pria \\
\hline & Solokuo & 1 & Sarjana & Wanita \\
\hline \multirow{5}{*}{ Probolinggo } & Bantaran & 1 & Mahasiswa & Pria \\
\hline & Leces & 1 & $\begin{array}{l}\text { Sekolah Menengah } \\
\text { Atas }\end{array}$ & Pria \\
\hline & Sumberasih & 1 & Mahasiswa & Pria \\
\hline & Mayangan & 1 & Mahasiswa Vokasi & Pria \\
\hline & Kanigaran & 1 & Mahasiswa & Pria \\
\hline \multirow{5}{*}{ Nganjuk } & Loceret & 1 & Mahasiswa & Wanita \\
\hline & Tanjung anom & 1 & Mahasiswa & Wanita \\
\hline & Ngroggot & 1 & $\begin{array}{l}\text { Sekolah Menengah } \\
\text { Atas }\end{array}$ & Wanita \\
\hline & Wilangan & 1 & Mahasiswa & Wanita \\
\hline & Pace & 1 & Mahasiswa & Wanita \\
\hline
\end{tabular}

Hasil pendaftaran peserta umum pengikut pelatihan pembuatan HS berbahan dasar non-alkohol sebanyak 19 peserta dengan lokasi aktivitas dan tingkat pendidikan serta kriteria lainnya sebagai berikut (Tabel 2).

Tabel 5.2. Peserta umum pelatihan pembuatan hand sanitizer berbasis non-alkohol

\begin{tabular}{llllc}
\hline \multicolumn{1}{c}{ Lokasi peserta } & \multicolumn{1}{c}{$\begin{array}{c}\text { Tingkat } \\
\text { pendidikan }\end{array}$} & Jenis kelamin & \multicolumn{1}{c}{ Keterangan } & Jumlah \\
\hline Surabaya-Indonesia & Doktor & Wanita & Dosen & 6 \\
\hline Surabaya-Indonesia & Magister & Wanita & $\begin{array}{l}\text { Dosen dan Dosen } \\
\text { Pasca Sarjana }\end{array}$ & 5 \\
\hline Banjarmasin - Indonesia & $\begin{array}{l}\text { Dokter gigi } \\
\text { spesialis } \\
\text { Orthodolology }\end{array}$ & Pria & $\begin{array}{l}\text { Dokter Rumah Sakit } \\
\text { Banjar Masin }\end{array}$ & 1 \\
\hline Perth-Australia & Sekolah Menegah & Wanita & Wiaswastawan & 1 \\
\hline
\end{tabular}


Mochamad Lazuardi, dkk: Pelatihan On-Line Pembuatan Perangkat Hand Sanitizer Berbahan Non-Alkohol Pada Pemuda Binaan

\begin{tabular}{|c|c|c|c|c|}
\hline & Atas & & & \\
\hline Madiun-Indonesia & $\begin{array}{l}\text { Sekolah } \\
\text { Menengah Atas }\end{array}$ & Pria & Wiraswastawan & 1 \\
\hline Mojokerto-Indonesia & $\begin{array}{l}\text { Sekolah } \\
\text { Menengah Atas }\end{array}$ & Wanita & Wiraswastawan & 1 \\
\hline Surabaya-Indonesia & $\begin{array}{l}\text { Sarjana } \\
\text { Kedokteran } \\
\text { Hewan }\end{array}$ & Pria & Mahasiswa & 2 \\
\hline Lamongan-Indonesia & $\begin{array}{l}\text { Sarjana } \\
\text { Matematia }\end{array}$ & Pria & Guru & 1 \\
\hline $\begin{array}{l}\text { Lamasi SulawesiSelatan } \\
\text { - Indonesia }\end{array}$ & Magister & Pria & Pegawai Negeri Sipil & 1 \\
\hline
\end{tabular}

Ditinjau dari hasil pelaksanaan tahap 1, menunjukkan seluruh peserta yang termasuk pemuda binaan dan peserta umum, hadir dengan jumlah kehadiran $100 \%$. Pada Gambar 5.1., dan Gambar 5.2 terlihat peserta dan tim pelaksana melakukan kegiatan pelatihan daring. Hasil analisis pasca pelatihan hari pertama menunjukkan bahwa hanya $20 \%$ yang mengetahui bahan-bahan yang dapat diguanakan sebagai HS, dan hanya $10 \%$ yang mengetahui dampak buruk penggunaan HS. Namun demikian hampir $60 \%$ mengetahui cara-cara penyimpanan HS yang aman dan benar selanjutnya hampir $70 \%$ mereka mengetahui manfaat formula HS menjadi komposisi solutio dan $65 \%$ mengetahui manfaat pengaturan asam-basa HS.

Lebih lanjut hasil evaluasi praktikum menunjukkan hasil seperti pada Tabel 3 di bawah :

Tabel 3. Analisis pengetahuan pemuda binaan pasca praktikum

\begin{tabular}{lccc}
\hline Pemuda binaan & $\begin{array}{l}\text { Memamahi tahapan } \\
\text { pembuatan HS (\%) }\end{array}$ & $\begin{array}{l}\text { Memahami cara } \\
\text { kualitas HS }(\%)\end{array}$ & $\begin{array}{c}\text { uji } \\
\text { kemahami ciri-ciri }\end{array}$ \\
\hline Probolinggo & 100 & 100 & 100 \\
\hline Nganjuk & 100 & 100 & 100 \\
\hline Bojonegoro & 80 & 80 & 80 \\
\hline Lamongan & 100 & 100 & 100 \\
\hline Gresik & 80 & 80 & 80 \\
\hline
\end{tabular}

Hasil analisis tabel 3., tersebut menunjukkan bahwa peserta pelatihan dari lima kabupaten pada umumnya sangat memahami muatan kompetensi yang diberikan pasca pembuatan HS melalui materi praktikum. Lebih lanjut hasil diskusi pada tahapan pelaksnaan tanggal 10 agustus 2020, menghasilkan ringkasan diskusi seperti pada Tabel 4 di bawah.

Tabel 4. Ringkasan diskusi pada pelatihan tahap evaluasi.

\begin{tabular}{|c|c|c|c|}
\hline Pemuda binaan & Peserta umum & $\begin{array}{l}\text { Testimoni } \\
\text { binaan }\end{array}$ & Keterangan \\
\hline $\begin{array}{l}\text { Menanyakan jenis } \\
\text { bahan-bahan kimia } \\
\text { pembentuk HS } \\
\text { non-alkohol yang bisa } \\
\text { digantikan sesuai } \\
\text { ketersediaan di } \\
\text { kabupatennya }\end{array}$ & $\begin{array}{l}\text { Mengharapkan akan } \\
\text { memproduksi sendiri, } \\
\text { karena sudah dapat } \\
\text { memahami pelatihan } \\
\text { ini }\end{array}$ & \multirow[t]{2}{*}{$\begin{array}{l}\text { Mampu membuat } \\
\text { produk HS non-alkohol } \\
\text { di wilayah kabupaten } \\
\text { masing-masing }(92 \%) \\
\text { Lampiran } 5 \text {. }\end{array}$} & $\begin{array}{l}\text { Jumlah pemuda binaan } \\
\text { yang memberikan } \\
\text { testimoni tidak mampu } \\
\text { membuat HS } \\
\text { non-alkohol }(4 \%)\end{array}$ \\
\hline $\begin{array}{l}\text { Izin menularkan } \\
\text { pengethuan dan }\end{array}$ & $\begin{array}{l}\text { Menghendaki dapat } \\
\text { diproduksi di }\end{array}$ & & $\begin{array}{l}\text { yang masih ragu untuk } \\
\text { membuat HS berbasis }\end{array}$ \\
\hline
\end{tabular}




\begin{tabular}{llc}
\hline ketrampiln kepada & Banjarmasin & non-alkohol (4 \%) \\
pemuda-pemudi lain di & & \\
kabupaten & & \\
masing-masing & & \\
\hline
\end{tabular}

\section{PENUTUP}

\section{Simpulan dan Saran}

Hasil pengerjaan pengabdian kepada masyarakat selam tiga hari dapat di simpukan; (1) Hasil pemberian penguatan kompetensi terhadap pemuda binaan di Kabupaten Bojonegoro Nganjuk Probolinggo Gresik dan Lamongan sebagian besar menjadikan para pemuda binaan makin mengetahui segala aspek mengenai Hand Sanitizer. Sebagai tambahan kesimpulan adalah; (2) para pemuda binaan sebagian besar menjadi trampil untuk membuat perangkat hand sanitizer berbasis non-alkohol. Mengingat hand sanitizer berbasi non-alkohol tidak berbahaya, maka (3) secara tidak langsung mendorong moril sebagian besar para pemuda binaan untuk memproduksi sendiri keperluan disekita lingkungannya dan tidak mustahil menularkan pada pemuda lainnya.

Terdapat beberapa saran yang dapat diberikan berkaitan pasca melakukan program pengabdian kepada masyarakat, sebagai berikut: Perlu dilakukan pemutakhiran hubungan terhadap mitra kabupaten Universitas Airlangga terkait kecepatan kemutakhiran data kecamatan di wilayah kabupaten tersebut. Perlu dilakukan unit khusus di kabupaten terkait hubungan antara Universitas Airlangga dan Kabupaten, semata-mata untuk memudahkan organisasi antara tim pengabdian masyarakat Universitas Airlangga dengan target wilayah di kabupaten tersebut. Perlu dilakukan pengabdian masyarakat sejenis dengan sebaran kabupaten di luar lima wilayah kabupaten mitra Universitas Airlangga, sehingga berimplikasi luas.

\section{DAFTAR PUSTAKA}

Ahmed Elzainy, Abir El Sadik, Waleed Al Abdulmonem. 2020. Experience of e-learning and online assessment during the COVID-19 pandemic at the College of Medicine, Qassim University. J. Taibah Univ. Medical Sci. doi: 10.1016/j.jtumed.2020.09.005.

Fawzieh Masa'd, 2017. Implementation of E-Training in Developing Country: Empirical Evidence from Jordan. Int. J. Bus. Res. 10 (4): 42-57.

Jane Lee Jia Jing, Thong Pei Yi, Rajendran J. C. Bose, Jason R. McCarthy, Nagendran Tharmalingam and Thiagarajan Madheswaran. 2020. Hand Sanitizers: A Review on Formulation Aspects, Adverse Effects, and Regulations. Int. J. Environ. Res. Public Health. 17,3326. Doi:10.3390/ijerph17093326.

Lazuardi M, Bambang H, Tjuk IR. 2019. Pelatihan penetapan waktu henti obat hewan. Surabaya: Airlangga University Press.

Lazuardi M, Hani P, Eka PH. 2020. Pelatihan On-Line Pembuatan Perangkat Hand Sanitizer Berbahan Non-Alkohol Pada Pemuda Binaan Di Kabupaten Bojonegoro Nganjuk Probolinggo Gresik Lamongan. Laporan akhir Pengabdian Kepada 
Masyarakat. Lembaga Penelitian dan Pengabdian Kepada Masyarakat Univ. Airlangga.

Lazuardi M. 2011. Panduan Model Pembelajaran Live Skill. Untuk Program Pendidikan Penulisan Resep Tingkat Dokter Hewan. Jakarta: Pandu Aksara Publishing.

United Nations Conference On Trade and Development, 2020.Trade and Development Report 2020 From Global Pandemc to Prosperity for All: avoiding another lost decade. United Nations Publications,300 East 42nd Street,New York, New York 10017,United States of America.

World Health Organization.2006. WHO Guidelines on Hand Hygiene in Health Care (advance draft).Genewa: Publications of the World Health Organization can be obtained from WHO Press, World Health Organization, 20 Avenue Appia, 1211 Geneva 27, Switzerland 